\title{
Integration of a MOOC into a traditional third-level e-learning platform
}

\section{Fuchs-Kittowski, Frank ${ }^{\mathrm{a}}$}

${ }^{a}$ Department of Engineering Technology \& Life, Hochschule für Technik und Wirtschaft (HTW) Berlin, Germany.

\begin{abstract}
This article presents the didactic concept and the Massive Open Online Course (MOOC) e-learning solution for the course "Environment, computer science and society" in the environmental informatics degree course at the HTW Berlin, which was realised on the basis of the traditional third-level learning platform Moodle.
\end{abstract}

Keywords: MOOC; integration; e-learning environment. 


\section{Introduction}

The "Environment, computer science and society" course was established as part of the environmental informatics degree at the HTW Berlin. Its aim is to provide a basic knowledge of the subject and to evolve, in particular, an outlook on the social and societal changes caused by information and communications technology (ICT). As well as raising awareness and developing a set of values, the course is designed to be action oriented as well as interdisciplinary. To this end, the didactic concept of the course includes interdisciplinary project work as well as lectures and seminars (see Fuchs-Kittowski \& Wohlgemuth (2016)). A further goal is to clarify how computer scientists can contribute to technically, socially, and ethically responsible computer usage through their work in information system design and software development.

Since the founding of the bachelor's degree course in environmental informatics, Klaus Fuchs-Kittowski has taught "Environment, computer science and society" (see FuchsKittowski (2013)). In order to preserve the special expertise and experience of this outstanding representative of the subject "computer science and society" and make it available to future generations of students as well as other interested parties, it was decided to digitally record the lectures and make them available as part of an e-learning environment. Within the framework of an in-house project of the HTW Berlin, e-learning support for this course was designed and implemented as a Massive Open Online Course (MOOC). A major challenge of this approach was the question of how to implement a MOOC within a traditional learning platform (Moodle).

This article is structured as follows: the goals and didactic concept of the course "Environment, computer science and society" in the environmental informatics degree at the HTW Berlin are described in Section 2. The objectives and requirements of the elearning solution are presented in Section 3 and the MOOC concept for this course is discussed in Section 4. Section 5 presents the technical implementation of the MOOC within the traditional learning environment Moodle. A summary and conclusion is provided in Section 6. 


\section{Didactic concept}

The course "Environment, computer science and society" aims, on the one hand, to provide a basic knowledge of the subject and thereby develop an outlook on the social and societal impact of ICT. On the other hand, it should also be action oriented and interdisciplinary so that future computer scientists can learn to take social and ethical aspects into account when working on system design and software development. In order to achieve this, the didactic concept includes interdisciplinary group project work (project component) in addition to seminar-like classes (lecture and seminar component).

The basic knowledge is taught through lectures on different topics. From the multitude of possible topics, those that introduce the themes of the environment, computer science, and society and are related to the subject of environmental informatics were chosen. In this way, a true foundation in the subject is achieved through appropriate fundamental knowledge.

The primary objective of the course is the formation of an outlook on the social and societal changes caused by the design and usage of ICT. This goal is achieved through numerous discussions during the lectures (seminar-like classes). The students are also encouraged to discuss information and experiences with their peers through group work and student presentations. This cultivates the collective opinion-forming process and improves the students' discourse skills.

The core feature of the project work is that students work independently on proposed themes within different project groups. The project structure is intended to facilitate problem-oriented work as well as research-based (see Huber (2009)) and experience-based (see Kolb (1975)) learning. The integrated, didactic project format also stimulates both individual and collective action. Positive experiences and outcomes help to build the students' faith in their own abilities and impact (power) and give them the confidence to continue on-going projects as well as start their own new projects and campaigns.

The interdisciplinary nature of environmental informatics is both a strength and a challenge. Students of environmental informatics must learn to design and implement computer systems in environmental fields within interdisciplinary collaborations. This certainly cannot be achieved in a single course. However, "Environment, computer science and society" is an essential building block in the process. As part of the course, project tasks, including an interdisciplinary questionnaire, are tackled by a group of several students. Additionally, one or more external experts from other disciplines are available to support and supervise the students in order to promote interdisciplinary cooperation. 


\section{Requirements}

The main goal of this work was to digitally preserve the course lectures in an e-learning environment and make them accessible to a wide audience as a web-based study opportunity without the need for physical presence. The MOOC is currently a widelydiscussed concept (see BIS (2013)) and has proved to be an important and useful addition to teaching methods at universities (see Klobas et al. (2015)). It can be especially helpful for teaching standard knowledge (see EFI (2015), p.15) and can also help to alleviate the lack of qualified teachers. Therefore, it was decided that the e-learning environment for this course should be realised as a MOOC.

In this case, the xMOOC concept (see Rodriguez (2012)) was used for the lecture component, as traditional lecturing methods (weekly lectures with slides and additional reading material) should be reflected by the system. The cMOOC (see Grünewald et al. (2013)) variant was more appropriate for the project component due to its more open, participatory approach. The students should have the chance to "attend" the lectures through video recordings and integrated presentation slides as well as find additional information and materials on the subject, e.g., books. They should also have the possibility to check their own knowledge through self-tests.

The HTW Berlin uses the world's most popular open source learning management system "Moodle" as its primary learning platform. Therefore, the e-learning environment for "Environment, computer science and society" should be implemented on this technical basis. However, Moodle is not designed as a MOOC platform and therefore some functionality must be expanded accordingly, something that would not be necessary if using an established MOOC platform such as iversity.org. The main advantage of using Moodle is that the eLearning Competence Centre provides (free) support for it at the HTW Berlin. This can be used for the development and operation of a customised e-learning environment. 


\section{Concept}

The lecture component begins together with the start of normal teaching (fixed start date). The course then offers a balanced schedule of nine consecutive course weeks (lectures). Each week, multimedia teaching material is provided that covers another chapter of the course "Environment, computer science and society". To this end, the students (course participants) are offered a series of lecture videos at the start of each week.

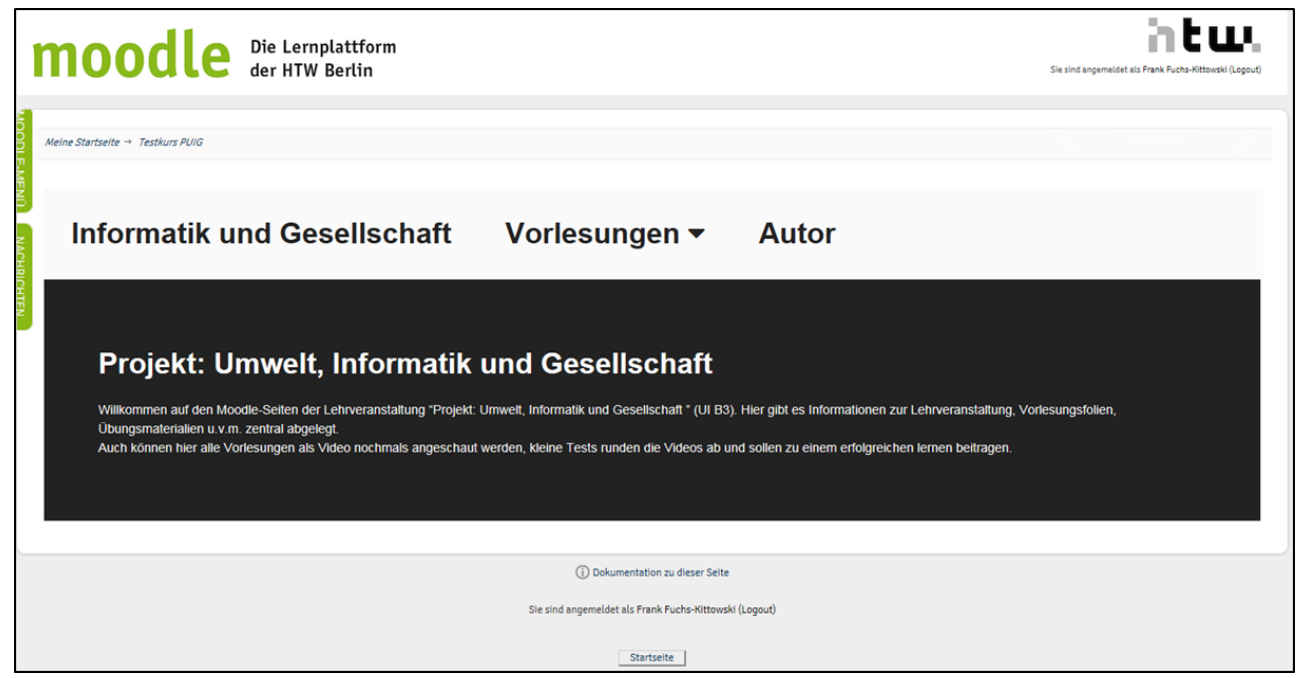

Figure 1. Start page of the e-learning environment for the course „Environment, computer science and society“

These videos were recorded and edited by the "Video production" project at the HTW Berlin. The lecture videos are accompanied by synchronised lecture slides. A progress bar is displayed at the bottom edge of the area containing the lecture video and slides. The bar also serves as a timeline, and clicking on the bar jumps the video to the corresponding location, i.e., forwards or backwards. It is also possible to display the video as well as the slides in full screen mode. 


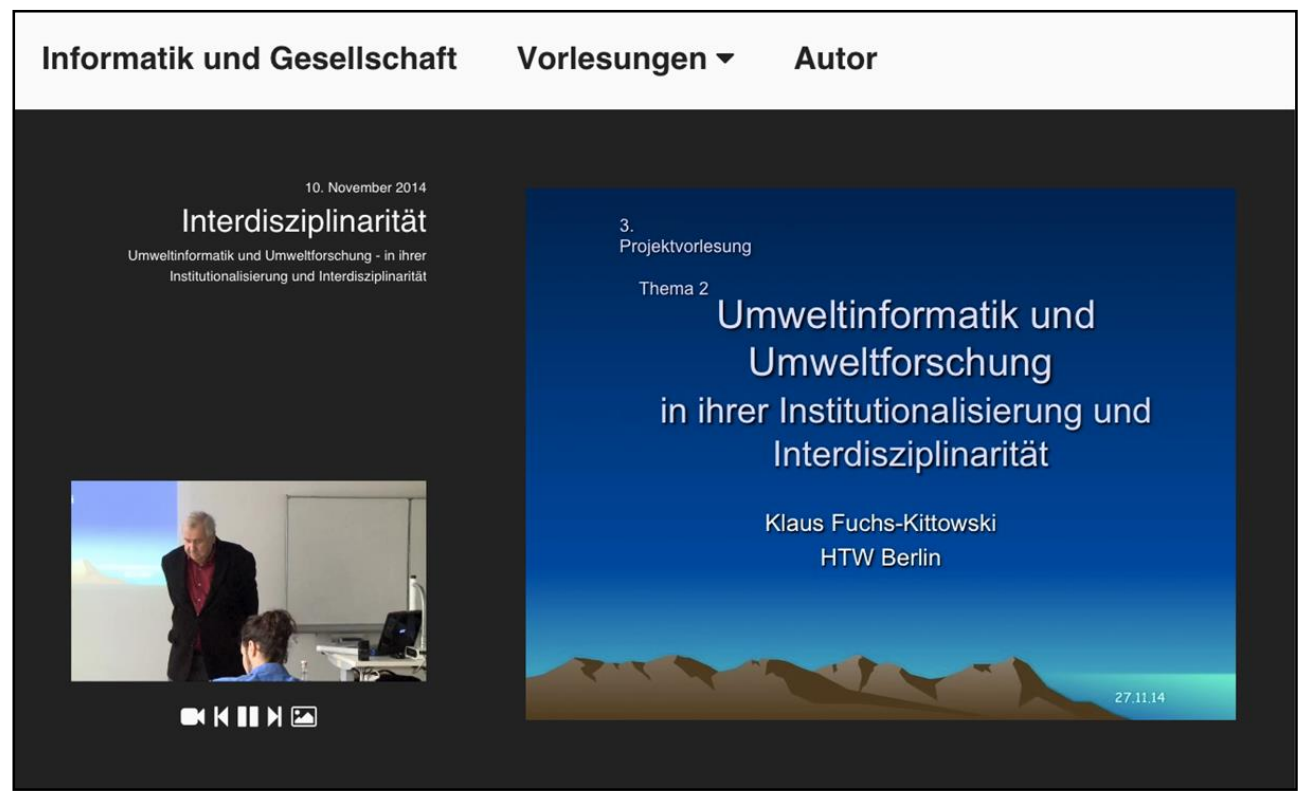

Figure 2. Lecture video with synchronised presentation slides

Additional material, supplementary to the lecture videos, is also provided. This can be in the form of extra information (downloadable content such as lecture slides, lecture notes, or publications by the lecturer, etc.), and book lists (books relevant to the lecture together with a short description and the ISBN), as well as interactive self-tests (see below) that the participants should address in a given week.

The self-tests help the course participants to monitor their learning progress. The can check for themselves if they have retained the most important knowledge from the previous videos. The tests pertain to a particular course week/lecture video, and pose questions on the material presented in that week. The different question types offered by the Moodle platform are used in the tests (e.g., fill-in-the-blank text, multiple choice questions, true/false questions, and matching questions). The students can thus obtain immediate feedback; their answers are automatically evaluated and the results are displayed immediately. The tests can be repeated as often as desired (the questions are permuted in each instance). 


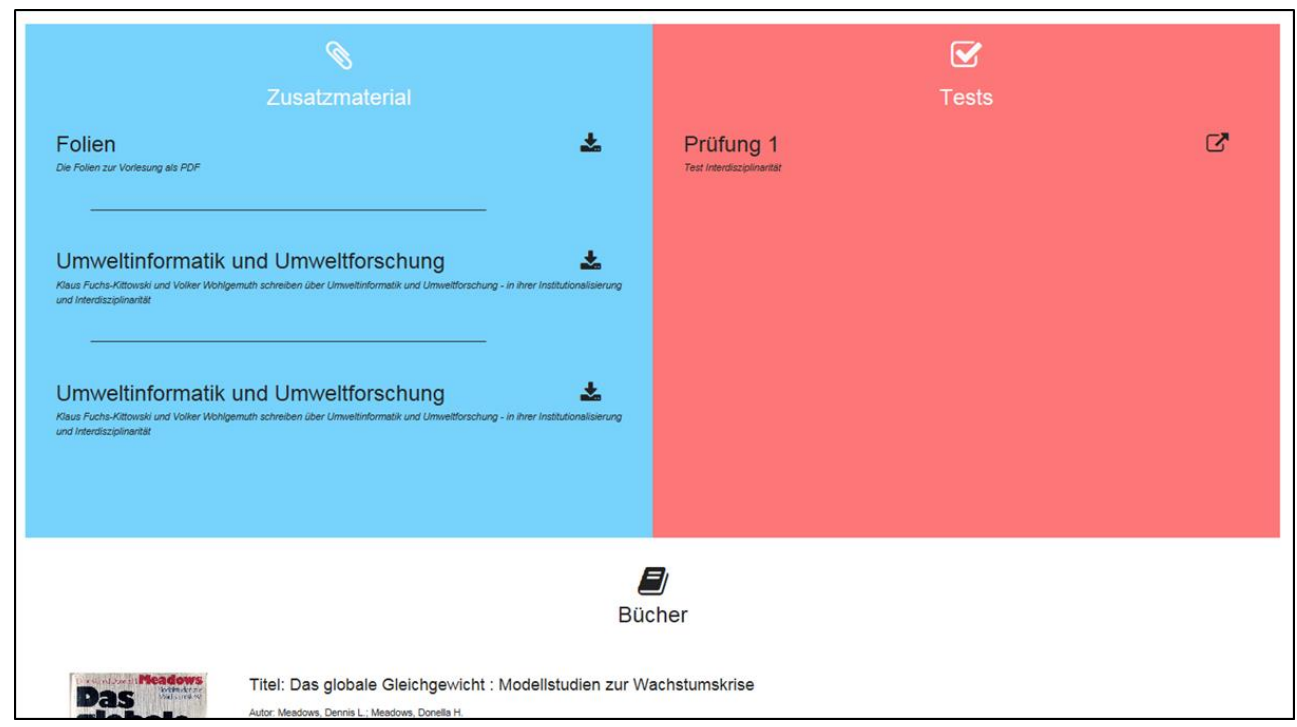

Figure 3. Area for additional material, booklists, and self-tests

A discussion forum is provided for each lecture topic, in which the students can clarify questions with the supervisors, exchange ideas with other students, or discuss further topics. Additionally, the students can find information on the career and expertise of the lecturer.

\section{Technical implementation}

A special feature of the MOOC used in this case is that it was not implemented in a typical MOOC platform (iVersity, Coursera, etc.), but as an extension of a classic learning platform (Moodle). The implementation was carried out by a project team consisting of five people, who participated in the course in the winter semester of 2014/15 (see Hiller et al. (2015)).

As of version 2.0, Moodle allows the platform to be individually customised, e.g., via HTML, CSS, and JavaScript files. In order to implement the additional features and MOOC-like layout required for this work, several web development frameworks were integrated into Moodle, such as jQuery, Bootstrap, and Font Awesome.

For example, the MOOC-like layout was achieved by overwriting the existing CSS rules provided by Moodle. Among other things, the typical Moodle menu on the right-hand side was converted into a retractable sidebar on the left-hand side, and the area usually available for a Moodle course was significantly increased.

The animated showing and hiding of content when using the menu in the upper area of the MOOC was achieved by changing the CSS properties of the affected elements and including the jQuery library which provides the animate() method. 
The display and control of the lecture video is achieved using the video tag available since HTML 5. This can be manipulated by JavaScript methods and events, e.g., in order to synchronise the lecture slides with the video playback.

\section{Summary and conclusion}

The subject of "computer science and society" appears in the curricula of computer science courses (including environmental informatics) in many German third-level institutions (see Kienle \& Grunau (2015)). However, there are hardly any university professorships in this subject in the country. Thus, only a few scientists and teachers are trained in this area, and the subject of "computer science and society" is generally taught by part-time teachers instead of full-time professors at many German third-level institutions.

At the HTW Berlin, the subject of "computer science and society" was first established as part of the business informatics course and then introduced into the environmental informatics course by Prof. Klaus Fuchs-Kittowski. In order to preserve the special expertise and experience of this outstanding representative of the subject and make it available for future generations of students, the lecture course was converted into a MOOC within the framework of a traditional third-level e-learning environment.

The MOOC has proven to be a useful tool over the course of two lecture cycles, especially for conveying standard knowledge, and can alleviate the lack of qualified teachers. In general, a MOOC cannot replace personal, individual classes or research-oriented teaching. However, in the case of "computer science and society", the formation of a set of values is dependent on personalised and contextual discussions of the topic and, for this, certain personalities are irreplaceable.

The implementation of the extension of moodle will be generalised to a moodle plugin. This plugin can be used by other moodle courses to use moodle as a MOOC platform. When finished the plugin will be made available as open source, e.g. via the official moodle plugin repository.

\section{References}

BIS (2013). The maturing of the MOOC: Literature review of massive open online courses and other forms of online distance learning. BIS Research Paper, Vol. 130. https://www.gov.uk/government/uploads/system/uploads/attachment_data/file/240193/1 3-1173-maturing-of-the-mooc.pdf

EC - European Commission (2015). Open Education Europe - The Gateway to Europe innovative Learning: Open Education Scoreboard. http://openeducationeuropa.eu/en/european_scoreboard_moocs (20.01.3017).

EFI - Expertenkommission Forschung und Innovation (2015). Gutachten zu Forschung, Innovation und Technologischer Leistungsfähigkeit Deutschlands. Berlin: EFI, http://www.e-fi.de/\#./fileadmin/Gutachten_2015/EFI_Gutachten_2015.pdf (27.1.2017). 
Fuchs-Kittowski, F. \& Wohlgemuth, V. (2016). Ziele, Inhalte, didaktisches Konzept und ELearning-Unterstützung der Lehrveranstaltung "Umwelt, Informatik und Gesellschaft" an der HTW Berlin. In: Informatik und Gesellschaft, S. 193-210, Peter Lang Verlag der Wissenschaften, Frankfurt am Main.

Fuchs-Kittowski, K. (2013). Umweltinformatik und Gesellschaft - Vorlesung und Projektarbeit an der Hochschule für Technik und Wirtschaft im Studiengang Umweltinformatik. In: Weltweite Datenausspähung / Informatik und Bildung, FIfFKommunikation, Heft 3, S. 54-59.

Grünewald, F., Mazandarani, E., Meinel, C., Teusner, R., Totschnig, M. \& Willems, C. (2013). openHPI: Soziales und Praktisches Lernen im Kontext eines MOOC. In: Andreas Breiter, Christoph Rensing (Hrsg.): 11. e-Learning Fachtagung Informatik (DeLFI 2013), GI-Edition-Lecture Notes in Informatics (LNI), P-218, Bonn: Bonner Köllen, S. 143-152.

Hiller, M., Sahre, T., Dengler, J., Uhlmann, M. \& Seewald, C. (2015). Online-Lehr- und Lern-Modul zur Lehrveranstaltung: Projekt - Umwelt - Informatik - Gesellschaft. Projektbericht, HTW Berlin.

Huber, L. (2009). Warum Forschendes Lernen nötig und möglich ist. In: Huber, Ludwig; Hellmer, Julia; Schneider, Friederike (Hg.): Forschendes Lernen im Studium. Aktuelle Konzepte und Erfahrungen, Bielefeld: Universität Webler, S. 9-35.

Kienle, A. \& Kunau, G. (2014). Informatik und Gesellschaft - Eine soziatechnische Perspektive. De Gruyter, Oldenbourg Wissenschaftsverlag.

Klobas, J. E., Mackintosh, B. \& Murphy, J. (2015). The Anatomy of MOOCS. In: P. Kim (Ed.), Massive Open Online Courses. The MOOC Revolution. New York \& London: Routledge.

Kolb, D.A. \& Fry, R. (1975). Toward an applied theory of Experiential Learning. In: Cary Cooper (Hrsg.): Theories of Group Process, London: John Wiley, S. 33-58.

Rodriguez, O.C. (2012). MOOCs and the AI-Stanford like Courses: Two Successful and Distinct Course Formats for MOOCs. In: Eur. Journal of Open, Distance and ELearning. http://www.eurodl.org/?p=archives \&year=2012\&halfyear=2\&article $=516$ (21.01.2017).

Rohs, M. \& Giehl, C. (2014). Evaluationsbericht zum Management 2.0 MOOC. In: Mathias Rohs (Hrsg.): Beiträge zur Erwachsenenbildung, Nr.1, Techn. Universität Kaiserslautern. 